\title{
MJN EFFECT OF SELF-CARE PROGRAM FOR PATIENTS USING COLOSTOMY AT MANSOURA CITY
}

\author{
Mayada Taha Mahmoud Sabea*, Taghreed Talat Shaqueer \\ Faculty of Nursing, Helwan University, Egypt \\ *Corresponding Author's Email: mayodataha@gmail.com
}

\begin{abstract}
Background: Colostomy means an artificial opening of the colon onto the abdominal surface. It may originate from: The sigmoid colon, the descending colon, the transverse colon or the ascending colon. the colostomy need care so that the patients can determine self-care to prevent complications. Aim: Evaluate effect of self-care program for patients using colostomy at Mansoura City. Design: A quasi-experimental research design. Setting: Conducted at the Surgical Outpatients Clinic in Mansoura University Hospital. Sample: A purposive sample (40) colostomy patients. Tools: An interviewing tools was used in this study divided to three parts, 1) Socio-demographic characteristics, 2) Patients' knowledge regarding colostomy, and 3) Patients' reported self-care practices toward colostomy. Results: The present study results showed that patients' total score knowledge pre self-care program was $14.4040 \pm 9.15423$, while after post self-care program it improved to $35.3200 \pm 6.9390$. As well, the results showed that total score reported self-care practices pre self-care program was $6.320 \pm 6.735$, which improved to $15.300 \pm 2.262$ post self-care program, with highly statistically significant differences. Conclusion: The self-care program improved patients' knowledge and reported self-care practices toward colostomy. Recommendations: This study recommended that a further research is needed to investigate the long-term effect of such educational intervention on the health of patients with colostomy and should be carried out on a larger number of colostomy patients for evidence of the results and generalization.
\end{abstract}

Keywords: Self-care Program; Patients Using Colostomy; Mansoura City

\section{INTRODUCTION}

A colostomy is named according to where in the bowel it is formed. It may be an ascending, transverse, descending, or sigmoid colostomy. The type of waste is dependent on the site of the bowel used such as the waste in colostomy (ascending colostomy) is liquid to mushy and bad odor, while waste in right transverse colostomy is mushy to semi-formed and waste in left transverse colostomy is semi-formed and soft, also the waste in descending or sigmoid colostomy is soft to hard formed. Approximately 700,000 Europeans have had surgery opening in colon to remove damaged portions of colon. Colon cancer is essential cause to apply colostomy opening. Colon cancer cause $4 \%$ of all cancer deaths (Black \& Matassarin-Jacobs, 2018).

The American Cancer Society showed that the colon cancer is the major cause of death between cancer patients in the United States, in 2016 the total of colostomy patients is $1,658,370$ of 589,430 (SEER Cancer Statistics Fact sheets, 2017). 77\% ( $\approx 3000)$ of people in the United Kingdom undergoing anterior resection for colon cancer will have end stoma formed and $27 \%$ will still have a stoma at 18 -month follow-up (American Cancer Society, 2019).

Colostomy is a surgery necessary when colon has been removed because of cancers tumors or other conditions. Colostomy often ends with a patient's stool leaving the body through the abdominal wall (Annual Statistics of the National Cancer Institute, 2017; Shariat, Milowsky \& Droller 2009).

Colostomy surgery may be temporary or permanent ostomy, the patient facing several conflicts to deal with this opening. A colostomy is an artificial opening in the bowel that has been made to bring the bowel onto the 
surface of the abdomen in order to divert the flow of stool. The colon cancer considers a significant serious health problem in the developing countries (Ferlay et al., 2018). The colostomy may be due to noncancerous cause like due to prevention and treatment of colorectal complications, including anastomotic leakage and parastomal hernia, or cancer cause such as colon cancer, rectal and anal cancer (AlHussein et al., 2015; Ferlay et al., 2010).

Self-care program aids the patients with colostomy to apply care to him/herself. So, the nurse should be able to provide knowledge and teach practices for patients with colostomy, that support the patient to avoid complications and self-care themself after hospital discharge. The nurse provide health education about nature of disease. Colostomy care include: care of skin surrounding stoma; appropriate diet; inform the patients signs and symptoms of infection; abnormalities and to avoid complications; follow up visits at outpatient clinics; and how empty the colostomy bag and stoma care (Goldberg et al., 2016; Luis et al., 2017; Hugar et al., 2016).

\section{Significance of the Study}

In Egypt, $7.8 \%$, and 8 new cases per hundred thousand people per year complain from colon cancer (Khaled, 2019). The American Cancer Society estimated that 74,000 adults would be diagnosed with colon cancer by 2015 in the United States. It will be estimated that 16,000 deaths from colostomy infection (American Cancer Society, 2019; Leow et al., 2018)

Above $85 \%$ of colon cancers are transitional cell in origin, while, in countries with high endemic parasitic diseases rates, such as Egypt, squamous cell carcinoma of the colon is more widespread (Nishikawa et al., 2018). Egypt represents the 13th level around the world of cancer incidence and 10th level in cancer mortality also in Egypt $21.8 \%$ among standardized rate per 100.000 were diagnosed with colon cancer and $13.1 \%$ cancer mortality rate (Ferlay et al., 2018).

The patients with colostomy faced conflict to care their stoma and that effect negatively in their psychological and physical status. So, the nurse play important role to teach these patients regarding the application of stoma opening self-care especially for patient complaining permanent colostomy (Zarzour et al., 2008).

\section{METHODOLOGY}

\section{Aim of the Study}

The study was applied to evaluate the effect of selfcare program for patients using colostomy at Mansoura City, Egypt.

\section{Research Hypothesis}

- Improvement in patients' knowledge regarding colostomy

- Improvement in patients' reported self-care practices regarding colostomy

\section{Subjects and Methods}

\section{Research design}

A quasi-experimental research design was utilized to achieve the aim of this study.

\section{Setting}

The study was conducted at the surgical outpatients' clinic in Mansoura University Hospital.

\section{Sample}

A purposive sample was used in this study. Patients diagnosed with colostomy at the surgical Outpatients' Clinics in Mansoura University Hospitals accounted for 400 patients in the year 2017-2018. The researchers selected $10 \%$ of them (40 patients for the main study sample, and 4 for pilot study) through the inclusion criteria: able to communicate and approved to participate in this study.

\section{Tools of Data Collection}

\section{An Interviewing Tool Divided to 3 Parts}

Part I: Questions regarding Socio-demographic characteristics: it included patient's age, gender, marital status, educational level, current occupation, monthly income, smokers, and residence place.

Part II: Patients' knowledge regarding colostomy, divided to: a) Patients' universal knowledge related to colostomy, such as: causes, signs and symptoms; preparations before colostomy surgery; exercise postoperatively; tubes will be applied after operation; immediate complications post operation, complications, warning signs to call physician immediately, normal range of stool elimination /day, and bowel elimination 
problems after surgery, b) Patients' knowledge related to colostomy bag and care of the stoma, such as: importance of hand washing before and after care, importance of observing stool such as color, smell, quantity, and consistency every day, importance of disinfection of scissor used to cut out the circle on the wafer colostomy bag, important of observing skin around stoma, reason of bringing all supplies during care, determine about when to empty the pouch, and importance of the bag not to keep longer than seven days, c) Patients' knowledge regarding appropriate diet such as: the time allowed to eat after surgery, healthy diet appropriate for colostomy surgery, healthy diet that does not cause bad odor for stool, diet that does not cause constipation, diet that does not cause gas formation, the diet that does not cause indigestion, diets that help in wound healing, and importance of drinking plenty of fluids throughout the day post-surgery.

Scoring System: A correct and complete answer scored 2, while incomplete correct answer scored 1, and didn't know or incorrect answer scored zero. The total score for all questions related to knowledge was 52 grades. The scores of the items were summed and total divided by the number of all items giving a mean score. Knowledge was evaluated poor if the answers $(<50 \%)$ scored from $(0-<25)$, while fair knowledge if the answers $(50-75 \%)$ scored from $(26-<39)$, and good knowledge if the answers ( $>75 \%)$ scored from (39-52).

Part III: Patients' reported self-care practices toward colostomy, such as: wash hands thoroughly using soap and water or use alcohol; gently take the pouch off; holding the skin with one hand, slowly ease pouch off using the built in tab for easier removal; check skin; check colostomy in general; clean stoma by using warm water and a dry wipe with mild soap on it; gently wipe around colostomy; also be sure to wash hands one more time before putting on the new pouch; use a skin barrier, such as colostomy powder; be careful not to put the powder on the colostomy itself. Carefully dust it around using a dry wipe; let the area dry for about 60 seconds; prepare the new pouch; use special disinfectant scissors to cut out the circle on the wafer; cut the wafer to fit the colostomy; place the wafer over the colostomy; begin pressing on the part of the flange located underneath the colostomy; gently moving to the sides and then to the top; once adhered, begin smoothing the flange to remove the creases; helps to form a tighter seal around the colostomy; hand washing after procedure.

Scoring System: 19 questions in this part, if the patient answer "Done" scored 1 and if answered "Not done" scored zero, the scores of the items were summed up and total divided by the number of all items giving a mean score. The total score was considered satisfactory if percent $(<50 \%)(0-<9)$ and unsatisfactory level if the percent score $(50 \%)(10-19)$

\section{Reliability}

- Patients' knowledge regarding colostomy, Cronbach's Alpha was 0.85 .

- Patients' reported self-care practices regarding colostomy care, Cronbach's Alpha $=0.82$.

\section{Validity}

The study tools were evaluated by 7 experts from medical surgical nursing and community health nursing, Faculty of Nursing, Mansoura University and Ain Shams University; two Surgeon from Faculty of Medicine, Helwan University. Their opinions were elicited regarding the formats, layout, consistency, accuracy and relevance of the tool and accordingly modifications were done.

\section{Pilot Study}

A pilot study was conducted on $10 \%$ of subjects (4 patients) to test the applicability and feasibility of study tool as well as to evaluate the time needed to fill the tool. Obtained results were used as a guide to take into consideration the changes needed in the data collection tool and those sample who participated in the pilot study were excluded from the main study sample.

\section{Ethical Considerations}

The researchers acquainted the patients who participated in the study, then they gained an oral consent. Even though they approved to participate in the study, they were allowed to withdraw from the study at any phase without giving any reason; they were also assured that privacy of information, and data collected will be used only for the purpose of the study and their benefits.

\section{Field Work}

- Sampling and data collection were beginning and 
completed within six months, from December 2018 to end of May 2019.

- The aim of study was simply clarified to patients who approved to participate in study previous to any data collection.

- The study was applied through four phases: assessment, planning, implementation, and evaluation.

\section{Assessment Phase}

- This was the first phase; the researchers welcomed the patients then introduced themselves to studied sample; the researchers collected socio-demographic characteristics from medical records as essential data, and then implemented a pretest questions to determine studied sample knowledge and reported self-care practices regarding colostomy.

- Data were collected from Mansoura University Hospital Outpatient Clinic by the researchers 3 days/week at morning shifts from $9.00 \mathrm{am}$. to $12.00 \mathrm{pm}$. The data were obtained individually by interviewing studied sample. The time spent to fill in the study tool was 20 minutes.

-A booklet and posters containing knowledge related to colostomy self-care was provided to patients.

-The self-care program was designed by the researchers, based on the results of assessment (pretest)

\section{Planning Phase}

- The self-care program was prepared by researchers based on analysis of the actual patients' requirements detected in pre assessment by using the pre-built tool.

-The self-care program was written in simple Arabic language that was proportionately related to literature to meet patients' requirements and their level of understanding.

-The self-care program was provided to patients through handouts and posters. It included figures, colored pictures which were primarily intended for attracting and guiding patients to actively participate in their self-care independently. The self-care was written in a simple way that could be understood easily by reader in self-learning.

- This self-care included two parts; theoretical part and practical part. The theoretical part covers the aim and care of colostomy.

\section{Implementation Phase}

- The self-care program was implemented to improve the subject knowledge and reported self-care practices regarding colostomy. It included:

- Patients' knowledge regarding colostomy as: important of hand washing before and after stoma care, important of observing stool for color, smell, quantity, and consistency every day.

- The self-care program was implemented in four sessions over a period of 6 months. The duration of each session ranged from 20 minutes, according to the knowledge of each session. The researchers met each patient individually and used some Medias as posters and simulation in practice sessions to increase attention. Also, sometimes the researchers provided counseling to patients through telephone calls.

- Each session started by a summary about what has been discussed in the previous session and gotten the aim of new session, the researchers using simple and clear language to be easy understandable by all patients with different educational levels.

- Each patient was made aware of the instructions given two times and the researchers used different methods of teaching including, brain storming, demonstration and re-demonstration. The researchers also were using colored poster. They distribute booklet to all patients. At the end of each session the patients determine the schedule of the next session.

\section{Evaluation Phase}

At the end of the sessions, the evaluation of the selfcare program was done immediately post implementation regarding their knowledge and reported self-care practices using the same questionnaire that was used in the pretest and assesse status of the colostomy.

\section{Statistical Design}

Data collected were statistically calculated by using the Statistical Package for Social Sciences (SPSS), version 22, (SPSS Inc. Chicago, IL, USA). For quantitative statistics, the range, mean and standard deviation were measured. For qualitative statistics, which define a conclusive establishment of data by 
frequency, percentage of each category. This was compared between pre and post program by using Chisquare test $\left(\chi^{2}\right)$. Correlation between variables was estimated using Paired $t$-test. Significance was adopted at $p<0.05$ for interpretation of results of tests of significance (Dawso \& Trapp, 2001).

\section{RESULTS}

Table 1: Distribution of Colostomy Patients Regarding Socio-Demographic Characteristics $(N=40)$

\begin{tabular}{|l|c|c|}
\hline Socio-demographic characteristics & No. & $\%$ \\
\hline Age & 4 & 10 \\
\hline $20: \leq 30$ years & 7 & 17.5 \\
\hline$>30: \leq 40$ years & 10 & 25 \\
\hline$>40: \leq 50$ years & 19 & 47.5 \\
\hline$>50-$ & 38 & 95 \\
\hline \multicolumn{3}{|c|}{ Mean \pm SD 40. 0176 $\pm \mathbf{5 . 6 5 7 1}$} \\
\hline Gender & 2 & 5 \\
\hline Male & 3 & 7.5 \\
\hline Female & 23 & 57.5 \\
\hline Marital status & 6 & 15 \\
\hline Single & 8 & 20 \\
\hline Married & \multicolumn{1}{|}{} \\
\hline Widowed & & \\
\hline Divorced & 38 \\
\hline
\end{tabular}

\begin{tabular}{|c|c|c|}
\hline \multicolumn{3}{|l|}{ Educational level } \\
\hline Illiterate & 16 & 40 \\
\hline read and write & 10 & 25 \\
\hline Primary education & 6 & 15 \\
\hline Preparatory education & 2 & 5 \\
\hline Secondary or diploma & 2 & 5 \\
\hline University and postgraduate & 4 & 10 \\
\hline \multicolumn{3}{|l|}{ Current occupation } \\
\hline Not work & 2 & 5 \\
\hline Housewife & 2 & 5 \\
\hline Free work & 14 & 35 \\
\hline Employee & 5 & 12.5 \\
\hline Retired & 17 & 42.5 \\
\hline \multicolumn{3}{|l|}{ Monthly income } \\
\hline Sufficient and saved & 3 & 7.5 \\
\hline Sufficient & 8 & 20 \\
\hline Insufficient & 29 & 72.5 \\
\hline \multicolumn{3}{|l|}{ Residence Place } \\
\hline Rural & 16 & 40 \\
\hline Urban & 24 & 60 \\
\hline
\end{tabular}

Table 1 showed that the mean age of studied patients was $40.0176 \pm 5.6571$. Regarding patients' gender, 95\% of studied sample were males, while $57.5 \%$ of them were married, and $40 \%$ of them were illiterates, as well as, the same table revealed that $42.5 \%$ and $72.5 \%$ of studied patients were retired and with insufficient monthly income respectively.

Table 2: Percentage Distribution of the Colostomy Patients' Correct Knowledge Regarding Colostomy Pre / Post $\operatorname{Program}(\mathrm{N}=40)$

\begin{tabular}{|c|c|c|c|}
\hline \multirow[b]{2}{*}{ Items } & \multicolumn{3}{|c|}{ Patients $n=40$} \\
\hline & Pre $\%$ & $\begin{array}{c}\text { Post } \\
\%\end{array}$ & $\begin{array}{l}\chi^{2} \\
P\end{array}$ \\
\hline \multicolumn{4}{|l|}{ Universal Knowledge, Through Determining the Following } \\
\hline Information about colostomy & 20 & 30 & $\begin{array}{l}14.529 \\
0.001^{*}\end{array}$ \\
\hline Causes of colostomy & 15 & 75 & $\begin{array}{l}10.869 \\
0.001 *\end{array}$ \\
\hline Signs and symptoms of colostomy & 10 & 50 & $\begin{array}{l}14.938 \\
0.001^{*}\end{array}$ \\
\hline Preparations before colostomy surgery & 5 & 80 & $\begin{array}{l}15.842 \\
0.001^{*}\end{array}$ \\
\hline Exercise postoperatively & 5 & 40 & $\begin{array}{l}15.646 \\
0.001^{*}\end{array}$ \\
\hline Tubes will be applied after operation & 15 & 60 & $\begin{array}{l}18.708 \\
0.001^{*} \\
\end{array}$ \\
\hline Immediate complications after the operation & 10 & 40 & $\begin{array}{l}3.148 \\
0.490\end{array}$ \\
\hline Complications that may occur long -term after surgery & 20 & 50 & $\begin{array}{l}7.629 \\
0.943\end{array}$ \\
\hline Warning signs that call immediate contact with the physician & 10 & 60 & $\begin{array}{l}18.704 \\
0.001^{*}\end{array}$ \\
\hline
\end{tabular}




\begin{tabular}{|c|c|c|c|}
\hline Normal range of stool elimination per day & 10 & 80 & $\begin{array}{l}13.848 \\
0.001^{*}\end{array}$ \\
\hline Bowel elimination problems after surgery & 10 & 50 & $\begin{array}{l}12.277 \\
0.001^{*}\end{array}$ \\
\hline \multicolumn{4}{|l|}{ Knowledge Related Colostomy Care (Through Determining Importance of the Following): } \\
\hline Important of hand washing before and after colostomy care & 10 & 60 & $\begin{array}{l}18.704 \\
0.001^{*}\end{array}$ \\
\hline Important of disinfectant of scissor used to cut out the circle on the wafer colostomy bag & 15 & 70 & $\begin{array}{l}17.870 \\
0.001^{*}\end{array}$ \\
\hline Important of observing stool for color, smell, quantity, and consistency every day & 20 & 90 & $\begin{array}{l}14.588 \\
0.001^{*}\end{array}$ \\
\hline Important of observing skin around stoma during changing the colostomy bag & 5 & 60 & $\begin{array}{l}17.801 \\
0.001^{*}\end{array}$ \\
\hline Reason of bring all supplies are within easy reach & 10 & 60 & $\begin{array}{l}18.704 \\
0.001^{*}\end{array}$ \\
\hline Determine about when to empty the pouch & 20 & 85 & $\begin{array}{l}13.658 \\
0.001^{*}\end{array}$ \\
\hline Important of the bag never stay longer than seven days & 10 & 75 & $\begin{array}{l}16.708 \\
0.001^{*}\end{array}$ \\
\hline
\end{tabular}

*Significant $(P<0.05)$

Table 2 revealed that, post program $75 \%$ of patients were rightly informed about causes of colostomy, in addition $80 \%$ of patients were informed about preparations before colostomy surgery, and $80 \%$ of patients were notified about normal range of stool elimination per day, $(P<0.001)$.

Table 3: Distribution of Colostomy Patients' Correct Knowledge Regarding Diet Pre/Post Program (N=40)

\begin{tabular}{|l|c|c|c|}
\hline \multirow{2}{*}{ Items } & \multicolumn{2}{c|}{ Patients n $=\mathbf{4 0}$} & \multirow{2}{*}{$\begin{array}{c}\mathbf{P}^{2} \\
\boldsymbol{P}\end{array}$} \\
\cline { 2 - 3 } & Pre $\%$ & Post $\%$ & $\begin{array}{l}18.708 \\
0.001^{*}\end{array}$ \\
\hline The time allowed to eat after surgery & 15 & 60 & $\begin{array}{l}18.704 \\
0.001^{*}\end{array}$ \\
\hline Healthy diet that appropriate for this surgery & 10 & 60 & $\begin{array}{l}10.727 \\
0.001^{*}\end{array}$ \\
\hline Healthy diet that does not cause bad odor for stool & 10 & 55 & $\begin{array}{l}17.801 \\
0.001^{*}\end{array}$ \\
\hline The diet that does not cause indigestion or dyspepsia & 5 & 60 & $\begin{array}{l}9.374 \\
0.052\end{array}$ \\
\hline Diet that does not cause gas forming & 20 & 75 & $\begin{array}{l}12.333 \\
0.001^{*}\end{array}$ \\
\hline Diet that does not cause constipation & 10 & 65 & $\begin{array}{l}10.542 \\
0.001^{*}\end{array}$ \\
\hline Diets that help in wound healing & 5 & 55 & $\begin{array}{l}18.708 \\
0.001^{*}\end{array}$ \\
\hline $\begin{array}{l}\text { Importance of drinking plenty of fluids throughout the } \\
\text { day postoperatively }\end{array}$ & 15 & 60 & \\
\hline
\end{tabular}

*Significant $(P<0.05)$

Table 3 showed that, post program $75 \%$ of the studied patients knew about diet that does not cause gas formation and $65 \%$ of them knew diet that does not cause constipation, $(P<0.001)$. 
Table 4: Total Scores' Knowledge among Colostomy Patients ( $=40)$

\begin{tabular}{|c|c|c|c|c|c|}
\hline \multirow{3}{*}{ Total Knowledge } & \multicolumn{5}{|c|}{ Total Knowledge of the studied subjects pre and post program $(n=40)$} \\
\hline & \multicolumn{2}{|c|}{ Pre } & \multicolumn{2}{|c|}{ Post } & \multirow{2}{*}{$\begin{array}{l}\chi^{2} \\
P\end{array}$} \\
\hline & No. & $\%$ & No. & $\%$ & \\
\hline \multicolumn{5}{|l|}{ Total Knowledge levels: } & \multirow{5}{*}{$\begin{array}{l}13.537 \\
0.001^{*}\end{array}$} \\
\hline Poor $(<50 \%)(0:<25)$ & 38 & 95 & 5 & 12.5 & \\
\hline Fair $(50-75 \%)(26:<39)$ & 2 & 5 & 19 & 47.5 & \\
\hline Good $(>75 \%)(39: 52)$ & 0 & 0 & 16 & 40 & \\
\hline $\begin{array}{l}\text { Range }(0-52) \\
\text { Mean } \pm \text { SD }\end{array}$ & \multicolumn{2}{|c|}{$\begin{array}{c}(0-24) \\
14.4040 \pm 9.15423\end{array}$} & & .9390 & \\
\hline $\begin{array}{l}\text { Paired } t \text {-test } \\
P\end{array}$ & & & & & \\
\hline
\end{tabular}

*Significant $(P<0.05)$

Table 4 represented that total scores' of knowledge among patients regarding colostomy the Mean \pm SD preprogram was $14.4040 \pm 9.15423$, which improved to

$35.3200 \pm 6.9390$ post program implementation respectively, $P<0.001$.

Table 5: Distribution of Patients' Reported Done Self-Care Practices Regarding Colostomy Care Pre/Post $\operatorname{Program}(\mathrm{N}=40)$.

\begin{tabular}{|c|c|c|c|}
\hline \multirow[b]{2}{*}{ Items } & \multicolumn{3}{|c|}{ Patients $n=40$} \\
\hline & Pre $\%$ & Post $\%$ & $\begin{array}{l}\chi^{2} \\
P\end{array}$ \\
\hline $\begin{array}{l}\text { Wash hands thoroughly using soap and water. If this is not possible, use } \\
\text { alcohol }\end{array}$ & 30 & 85 & $\begin{array}{l}17.953 \\
0.0001^{*}\end{array}$ \\
\hline Gently take the pouch off & 10 & 75 & $\begin{array}{l}16.708 \\
0.001^{*}\end{array}$ \\
\hline $\begin{array}{l}\text { Holding the skin with one hand, slowly ease the pouch off using the built -in } \\
\text { tab for easier removal }\end{array}$ & 75 & 90 & $\begin{array}{c}4.028 \\
0.44 \\
\end{array}$ \\
\hline Check the skin & 45 & 85 & $\begin{array}{c}8.917 \\
0.0001^{*}\end{array}$ \\
\hline check the colostomy in general & 45 & 90 & $\begin{array}{l}5.182 \\
0.031 \\
\end{array}$ \\
\hline Clean the stoma by using warm water and a dry wipe with mild soap on it & 70 & 85 & $\begin{array}{r}3.207 \\
0.44 \\
\end{array}$ \\
\hline Gently wipe around the colostomy & 25 & 85 & $\begin{array}{l}11.952 \\
0.001^{*}\end{array}$ \\
\hline Also be sure to wash hands one more time before putting on the new pouch. & 15 & 85 & $\begin{array}{l}10.154 \\
0.001^{*}\end{array}$ \\
\hline Use a skin barrier, such as colostomy powder & 25 & 75 & $\begin{array}{l}10.327 \\
0.001^{*}\end{array}$ \\
\hline $\begin{array}{l}\text { Be careful not to put the powder on the colostomy itself. Carefully dust it } \\
\text { around using a dry wipe }\end{array}$ & 5 & 80 & $\begin{array}{l}15.842 \\
0.001^{*}\end{array}$ \\
\hline Let the area dry for about 60 seconds & 10 & 75 & $\begin{array}{l}16.708 \\
0.001 *\end{array}$ \\
\hline Prepa re the new pouch & 15 & 80 & $\begin{array}{r}9.689 \\
0.001 *\end{array}$ \\
\hline Use special disinfectant scissors to cut out the circle on the wafer & 20 & 65 & $\begin{array}{c}9.574 \\
0.001 *\end{array}$ \\
\hline Cut the wafer to fit the colostomy & 25 & 75 & $\begin{array}{l}10.327 \\
0.001^{*}\end{array}$ \\
\hline Place the wafer over the colostomy & 30 & 85 & $\begin{array}{l}12.472 \\
0.001^{*}\end{array}$ \\
\hline Begin pressing o $\mathrm{n}$ the part of the flange located underneath the colostomy & 80 & 95 & $\begin{array}{r}4.954 \\
0.023\end{array}$ \\
\hline Gently moving to the sides and then to the top & 20 & 70 & $\begin{array}{c}9.896 \\
0.001 *\end{array}$ \\
\hline $\begin{array}{l}\text { Once adhered, begin smoothing the flange to remove the creases. Doing this } \\
\text { helps to form a tighter seal around the colostomy }\end{array}$ & 25 & 80 & $\begin{array}{l}12.987 \\
0.001^{*}\end{array}$ \\
\hline
\end{tabular}

*Significant $(P<0.05)$

82 | VOL. 12 (3) January 2021 | THE MALAYSIAN JOURNAL OF NURSING 
Table 5 showed that there were no statistically significant differences among the studied patients regarding colostomy care pre/post program, $P>0.05$ at all items except; holding the skin with one hand, slowly ease the pouch off using the built in tab for easier removal; clean the colostomy by using warm water and a dry wipe with mild soap on it; and begin pressing on the part of the flange located underneath the colostomy.

Table 6: Distribution of Patients' Reported Done Self-Care Practices Regarding Colostomy Care Pre/Post Program $(N=40)$

\begin{tabular}{|c|c|c|c|}
\hline \multirow[b]{2}{*}{ Items } & \multicolumn{3}{|c|}{ Patients $n=40$} \\
\hline & Pre \% & Post \% & $\begin{array}{l}\chi^{2} \\
P\end{array}$ \\
\hline $\begin{array}{l}\text { Wash hands thoroughly using soap and water. If this is not possible, } \\
\text { use alcohol }\end{array}$ & 30 & 85 & $\begin{array}{l}17.953 \\
0.0001 *\end{array}$ \\
\hline Gently take the pouch off & 10 & 75 & $\begin{array}{l}16.708 \\
0.001 *\end{array}$ \\
\hline $\begin{array}{l}\text { Holding the skin with one hand, slowly ease the pouch off using the } \\
\text { built-in tab for easier removal }\end{array}$ & 75 & 90 & $\begin{array}{c}4.028 \\
0.44\end{array}$ \\
\hline Check the skin. & 45 & 85 & $\begin{array}{c}8.917 \\
0.0001 *\end{array}$ \\
\hline check the colostomy in general & 45 & 90 & $\begin{array}{l}5.182 \\
0.031\end{array}$ \\
\hline $\begin{array}{l}\text { Clean the stoma by using warm water and a dry wipe with mild soap } \\
\text { on it }\end{array}$ & 70 & 85 & $\begin{array}{r}3.207 \\
0.44\end{array}$ \\
\hline Gently wipe around the colostomy & 25 & 85 & $\begin{array}{l}11.952 \\
0.001^{*}\end{array}$ \\
\hline $\begin{array}{l}\text { Also be sure to wash hands one more time before putting on the new } \\
\text { pouch }\end{array}$ & 15 & 85 & $\begin{array}{l}10.154 \\
0.001 *\end{array}$ \\
\hline Use a skin barrier, such as colostomy powder & 25 & 75 & $\begin{array}{l}10.327 \\
0.001 *\end{array}$ \\
\hline $\begin{array}{l}\text { Be careful not to put the powder on the colostomy itself. Carefully } \\
\text { dust it around using a dry wipe }\end{array}$ & 5 & 80 & $\begin{array}{l}15.842 \\
0.001 *\end{array}$ \\
\hline Let the area dry for about 60 seconds & 10 & 75 & $\begin{array}{l}16.708 \\
0.001 *\end{array}$ \\
\hline Prepare the new pouch & 15 & 80 & $\begin{array}{c}9.689 \\
0.001 *\end{array}$ \\
\hline Use special disinfectant scissors to cut out the circle on the wafer & 20 & 65 & $\begin{array}{c}9.574 \\
0.001 * \\
\end{array}$ \\
\hline Cut the wafer to fit the colostomy & 25 & 75 & $\begin{array}{l}10.327 \\
0.001 *\end{array}$ \\
\hline Place the wafer over the colostomy & 30 & 85 & $\begin{array}{l}12.472 \\
0.001 *\end{array}$ \\
\hline $\begin{array}{l}\text { Begin pressing on the part of the flange located underneath the } \\
\text { colostomy }\end{array}$ & 80 & 95 & $\begin{array}{r}4.954 \\
0.023\end{array}$ \\
\hline Gently moving to the sides and then to the top & 20 & 70 & $\begin{array}{c}9.896 \\
0.001 *\end{array}$ \\
\hline $\begin{array}{l}\text { Once adhered, begin smoothing the flange to remove the creases. } \\
\text { Doing this helps to form a tighter seal around the colostomy }\end{array}$ & 25 & 80 & $\begin{array}{l}12.987 \\
0.001 *\end{array}$ \\
\hline Hand washing after the procedure & 65 & 85 & $\begin{array}{c}18.487 \\
0.0001 *\end{array}$ \\
\hline
\end{tabular}

*Significant $(P<0.05)$

Table 6 revealed that improvement in total scores reported self-care practices among colostomy patients regarding colostomy care post program, $(P<0.001)$. 
Table 7: Total Scores Reported Self-care Practices Among Colostomy Patients Regarding Colostomy Care $(N=40)$

\begin{tabular}{|c|c|c|c|c|c|}
\hline \multirow{3}{*}{ Total Reported Self -Care Practices } & \multicolumn{5}{|c|}{$\begin{array}{l}\text { Total Reported Practicecolostomy Patients pre and Post Program } \\
\qquad(\mathrm{n}=40)\end{array}$} \\
\hline & \multicolumn{2}{|c|}{ Pre } & \multicolumn{2}{|c|}{ Post } & \multirow{2}{*}{$\begin{array}{l}\chi^{2} \\
P\end{array}$} \\
\hline & No. & $\%$ & No. & $\%$ & \\
\hline \multicolumn{5}{|l|}{ Total reported Practice levels: } & \multirow{3}{*}{$\begin{array}{l}0.973 \\
0.001^{*}\end{array}$} \\
\hline Satisfactory $(<50 \%)(0-<9)$ & 8 & 20 & 38 & 95 & \\
\hline Unsatisfactory $(50 \%)(10-19)$ & 32 & 80 & 2 & 5 & \\
\hline $\begin{array}{l}\text { Range }(0-19) \\
\text { Mean } \pm \text { SD }\end{array}$ & \multicolumn{2}{|c|}{$\begin{array}{c}0-9 \\
6.320 \pm 6.735\end{array}$} & \multicolumn{2}{|c|}{$\begin{array}{c}10-19 \\
15.300 \pm 2.262\end{array}$} & \\
\hline $\begin{array}{l}\text { Paired } t \text {-test } \\
P\end{array}$ & \multicolumn{4}{|c|}{$\begin{array}{l}0.884 \\
0.001^{*}\end{array}$} & \\
\hline
\end{tabular}

Table 7 represented that there were positive significant correlations between total scores of patients' knowledge

and reported self-care practices among the studied patients pre / post program implementation, $(P<0.001)$.

Table 8: Correlation between Total Score Knowledge and Total Score Reported self-care practices of Colostomy Patients Pre/Post Program ( $N=40)$

\begin{tabular}{|c|c|c|c|c|c|c|}
\hline \multirow{3}{*}{ Variables } & \multicolumn{6}{|c|}{ Total score reported practice } \\
\hline & \multicolumn{3}{|c|}{ Pre } & \multicolumn{3}{|c|}{ Post } \\
\hline & $\begin{array}{c}\text { Paired } \\
t \text {-test }\end{array}$ & Mean \pm SD & $P$ & Paired t-test & Mean \pm SD & $P$ \\
\hline Total knowledge scores & 7.854 & $6.102000 \pm 10.313540$ & $0.001^{*}$ & 26.078 & $22.02000 \pm 6.252402$ & $0.001^{*}$ \\
\hline
\end{tabular}

*Significant $(P<0.05)$

\section{DISCUSSION}

A colostomy is a path that goes from the large intestine to the outside human abdomen. This helps solid waste and gas exit the body without passing through the rectum. The waste was collected in a pouch worn outside of human body. Before colostomy surgery the nurse and surgeon should be showed the best location for stoma, to let the patient be able see it easily and can take care of it by him/herself (Gacci et al., 2013).

The current study was conducted to evaluate the effect of self-care program for patients with colostomy, the results in the present study showed that, $47.5 \%$ of studied sample aged 50 years or more. This study finding cleared that $95 \%$ of studied sample was male, while $57.5 \%$ of them were married, and less than half $(40 \%)$ of them were illiterate. These results agree with those of Elhoty, (2017), who conducted a study on surgery departments and outpatient clinics at Al Qasr Al Aini Hospital, and reported that $85 \%$ of his studied sample was aged more than 50 years, males, and married, also the study was going in the same direction of the current study as it showed that half of study sample was illiterate.

Regarding the studied sample current occupation, this study result showed that more than half $(42.5 \%)$ of the sample was retired. This finding was consistent with that of Sack et al., (2016) which reported that $82 \%$ of their studied patients were retired.

The present study result showed that more than three quarters of studied sample reported that they had insufficient monthly income. This result disagrees with that of Klaassen et al., (2016), who found that 53\% of patients under study were in average economic status.

Concerning smoking, the current study finding discovered that $50 \%$ of the studied sample was smokers. This finding was corresponding with that of Miller et al., (2016) conducted in America showed that, 50\% of their studied subjects were smokers. The researchers' views 
that smoking was one of the causes of colon cancer.

Regarding patients residence, the present study result revealed that two thirds $(60 \%)$ of them were living in urban areas, this result agrees with that of Elhoty, (2017), who found that $61.7 \%$ of his studied sample was residing in urban areas, also it is incongruent with that of Mohamed, (2018), who found $82 \%$ of the studied sample was living in urban areas.

Considering patients' knowledge toward colostomy post self-care program implementation, the present study results showed that, three quarter $(75 \%)$ defined the causes of colostomy, in addition majority $(80 \%)$ of them were informed about preparations before colostomy surgery. This result was in accordance with that of Abufaraj et al., (2016), who reported that, 73\% of studied sample improvement in the patients' knowledge post program toward causes of colostomy. These results were congruent with those of Large et al., (2018), who carried out a study, at United States of America, who reported that, an improvement in the patients' knowledge post program regarding preparations before colostomy surgery. The researchers noted lack of knowledge about these items before program which improved post program in most of the items.

Related to patients' knowledge regarding appropriate diet for colostomy patients, the finding of current study discovered an improvement in their knowledge post program with highly statistically significant differences in some items. This result is in line with that of Gregg et al., (2017) which reported an improvement in the patients' diet and knowledge post program than before with statistically significant differences.

The current study presented that the Mean \pm SD of patients' total scores' knowledge regarding colostomy post program improved than pre-program, with highly statistically significant difference. This finding was in agreement with that of Mohamed et al., (2017) who in a very recent study conducted at the Surgery Unit of The General Surgical Department and Outpatient Clinic in Benha Teaching Hospital, mentioned an improvement of patients' total score knowledge post program, combined with highly statistically significant differences.

Regarding patients' total scores reported self-care practices regarding colostomy care, the present study results showed that, there was an improvement in patients' total scores reported self-care practices regarding colostomy care post program. This result corresponds with, that of (Nygren et al., 2019) who showed that, total scores' practices regarding colostomy care improved post application program, with highly statistically significant difference. The researchers attribute differences in the finding to insufficient patients' knowledge regarding colostomy care before program implementation and its improvement post implementation.

With reference to correlation between total scores of patients' knowledge and total score reported self-care practices regarding colostomy, the current study finding presented that there were positive significant correlations between total scores of patients' knowledge and reported self-care practices pre/post program. These results were similar with Ahmadi et al., (2016) in their study that revealed positive significant correlation between total scores of patients' knowledge and practices. Similarly, Nazmy et al., (2014) studies in Indiana City, found positive correlation between total scores of patients' knowledge and practices post program, also these results were congruent with those of Al-Maskari et al., (2017). This study revealed positive significant correlation between total scores of patients' knowledge and practices.

\section{CONCLUSION}

According to the current study results and research hypothesis, the present study revealed that there were statistically significant improvements in post self-care program implementation regarding all items of colostomy patients' knowledge than pre-test. As well, there were improvements in the studied sample reported self-care practices toward colostomy care post self-care program than pre, with highly statistically significant differences.

\section{Recommendations}

- Periodic implementation of the designed self-care guideline booklets for patients with cancer in the clinics, outpatients and hospitals at patients' admission to provide them with the necessary and required knowledge and self-care practices about their disease is mandatory.

- Further research is needed to investigate the longterm effect of such educational intervention on the health of patients with colostomy and should be carried out on a larger number of colostomy patients for evidence of the results and generalization. 


\section{Conflict of Interests}

The authors declare that they have no conflict of interest.

\section{ACKNOWLEDGEMENT}

The authors are thankful to the institutional authority for completion of the work.

\section{REFERENCES}

Abufaraj, M., Gust, K., Moschini, M., Foerster, B., Soria, F., Mathieu, R. \& Shariat, S.F. (2016). Management of muscle invasive, locally advanced and metastatic carcinoma of the colon: A literature review with emphasis on the role of surgery. Translational Andrology and Surgical, 5(5), pp 735-744.

Ahmadi, H., Skinner, E.C., Simma-Chiang, V., Miranda, G., Cai, J., Penson, D.F. \& Daneshmand, S. (2016). Colon Functional Outcome Following Radical Colostomy. The Journal of Surgical, 189(5), pp 1782-1788.

Al Hussein Al Awamlh, B., Wang, L.C., Nguyen, D.P., Rieken, M., Lee, R.K., Lee, D.J., Flynn, T., Chrystal, J., Shariat, S.F. \& Scherr, D.S. (2015). Is continent cutaneous urinary diversion a suitable alternative to orthotopic bladder substitute and ileal conduit after cystectomy?. BJU International, 116(5), pp 805-814.

Al-Maskari, F., El-Sadig, M., Al-Kaabi, J.M., Afandi, B., Nagelkerke, N. \& Yeatts, K.B. (2013). Knowledge, attitude and practices of diabetic patients in the United Arab Emirates. PloS One, 8(1), p e52857.

American Cancer Society (2019). Retrieved from: www.cancer .org/cancer/bladdercancer / detailedguide / colon-cancer -key-statistics

Annual Statistics of the National Cancer Institute (2017). Retrieved from: https://www.cancer.gov/aboutcancer/understanding/statistics

Black, J.M. \& Matassarin-Jacobs E. (2018). Medical-surgical nursing: clinical management for continuity of care $\left(5^{\text {th }}\right.$ ed.). Saunders, Philadelphia, pp 1582-1595.

Dawson, B.D. \& Trapp, R.G. (2001). Reading the medical literature: Basic \& clinical biostatistics (3rd ed.). Newyork: Lange Medical Book/McGraw-Hill. Medical Publication Division, Ch. 7-9, pp. 161-218 and Ch. 13, pp 305-314.

Elhoty, M.A. (2017). Assessment of physical and psychosocial needs in patients undergoing colostomy, Thesis for Master Degree in Medical Surgical Nursing, Faculty of Nursing, Helwan University, pp146-169.

Ferlay, J., Soerjomataram, I., Ervik, M., Dikshit, R., Eser, S., Mathers, C., Rebelo, M., Parkin, D.M., Forman, D. \& Bray, F. (2018). Cancer Incidence and Mortality Worldwide: IARC CancerBase No. 11. GLOBOCAN 2012 v1. 02013. Retrieved from: http://globocan.iarc.fr

Ferlay, J.S.H.R., Shin, H.R., Bray, F., Forman, D., Mathers, C. \& Parkin, D.M. (2010). Cancer incidence and mortality worldwide. Lyon: International Agency for Research on Cancer.

Gacci, M., Saleh, O., Cai, T., Gore, J.L., D’Elia, C., Minervini, A., Masieri, L., Giannessi, C., Lanciotti, M., Varca, V. \& Simonato, A. (2013). Quality of life in women undergoing urinary diversion for bladder cancer: results of a multicenter study among long-term disease-free survivors. Health and Quality of Life Outcomes, 11(1), pp 1-6.

Goldberg, H., Baniel, J., Mano, R., Rotlevy, G., Kedar, D. \& Yossepowitch, O. (2016). Orthotopic neo bladder vs. ileal conduit urinary diversion: a long-term quality-of-life comparison. In Urologic Oncology: Seminars and Original Investigations (Vol. 34, No. 3, pp. 121-e1). Elsevier.

Gregg, J.R., Cookson, M.S., Phillips, S., Salem, S., Chang, S.S., Clark, P.E. \& Barocas, D.A. (2017). Effect of preoperative nutritional deficiency on mortality after radical cystectomy for bladder cancer. The Journal of Surgical Medicine, 185(1), pp 90-96.

Hugar, L.A., Turner, R.M., Gusenoff, J.A., Correa, A.F., Jacobs, B.L. \& Davies, B.J. (2016). Panniculectomy and Cystectomy:An Approach to the Morbidly Obese Patient. Case Reports in Urology, 2016. 
Khaled, H. (2019). Fourth International Conference of the Egyptian Society for Liver Cancer; Retrived from: www.alhayat.com

Klaassen, Z., DiBianco, J.M., Jen, R.P., Harper, B., Yaguchi, G., Reinstatler, L. \& Madi, R. (2016). The impact of radical cystectomy and colostomy on suicidal death in patients with bladder cancer. Journal of Wound, Ostomy and Continence Nursing, 43(2), pp 152-157.

Large, M.C., Kiriluk, K.J., DeCastro, G.J., Patel, A.R., Prasad, S., Jayram, G. \& Steinberg, G.D. (2018). The impact of mechanical bowel preparation on postoperative complications for patients undergoing cystectomy and colostomy. The Journal of Surgical Medicine, 188(5), pp 1801-1805.

Leow, J.J., Reese, S., Trinh, Q.D., Bellmunt, J., Chung, B.I., Kibel, A.S. \& Chang, S.L. (2018). Impact of surgeon volume on the morbidity and costs of radical cystectomy in the USA: A contemporary population-based analysis. BJU International, 115(5), pp 713-721

Luis, D.A., Raed, A.A., Andre, B.K., Sameer, C. \& Arnaud, M. (2017). Robotic implantation of biodegradable regenerative colon conduit: experimental study. Journal of Surgical, 29(1), pp 52-57.

Miller, K.D., Siegel, R.L., Lin, C.C., Mariotto, A.B., Kramer, J.L., Rowland, J.H., Stein, K.D., Alteri, R. \& Jemal, A., (2016). Cancer treatment and survivorship statistics, 2016. CA: A Cancer Journal for Clinicians, 66(4), pp 271-289.

Mohamed, S.H. (2018). The effect of health teaching programme on the patient self-care related to colostomy at Zagazig University Hospitals, Thesis for Doctorate Degree In Medical Surgical Nursing, Faculty of Nursing Zagazig University, p 131.

Mohamed, S.S., Salem, G.M. \& Mohamed, H.A. (2017). Effect of self-care management program on self-efficacy among patients with colostomy. American Journal of Nursing, 5(5), pp 191-199.

Nazmy, M., Yuh, B., Kawachi, M., Lau, C.S., Linehan, J., Ruel, N.H., Torrey, R.R., Yamzon, J., Wilson, T.G. \& Chan, K.G. (2014). Early and late complications of robot-assisted radical cystectomy: a standardized analysis by urinary diversion type. The Journal of Urology, 191(3), pp 681-687.

Nishikawa, M., Miyake, H., Yamashita, M., Inoue, T. \& Fujisawa, M. (2018). Long-term changes in renal function outcomes following radical cystectomy and colostomy. International Journal of Clinical Oncology, 19(6), pp $1105-11111$.

Nygren, J., Thacker, J., Carli, F., Fearon, K.C.H., Norderval, S., Lobo, D.N. \& Ramirez, J. (2019). Guidelines for colostomy care. World Journal of Surgery, 37(2), pp 285-305.

Sack, B.S., Langenstroer, P., Guralnick, M.L., Jacobsohn, K.M. \& O’Connor, R. (2016). Cystectomy and colostomy for the management of a devastated lower colon following radiotherapy. Wisconsin Medical Society Journal, 115(2), pp $127-130$

SEER Cancer Statistics Fact sheets (2017). colostomy Cancer National Cancer Institute. Bethesda, MD; Retrieved from: http://seer.cancer.gov/statfacts/html/urinb.html

Shariat, S.F., Milowsky, M. \& Droller, M.J. (2009). November. Bladder cancer in the elderly. In Urologic Oncology: Seminars and Original Investigations (Vol. 27, No. 6, pp. 653-667). Elsevier.

Zarzour, A.H., Selim, M., Abd-Elsayed, A.A., Hameed, D.A. \& AbdelAziz, M.A. (2008). Muscle invasive bladder cancer in Upper Egypt: the shift in risk factors and tumor characteristics. BMC cancer, 8(1), p.250. 